\title{
Second to fourth digit ratio (2D:4D), breast cancer risk factors, and breast cancer risk: a prospective cohort study
}

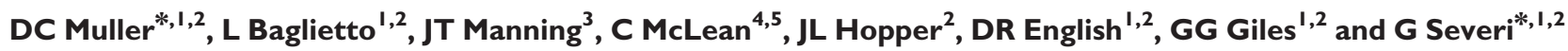 \\ 'Cancer Epidemiology Centre, Cancer Council Victoria, 100 Drummond Street, Carlton South, Victoria 3053, Australia; ${ }^{2}$ Centre for MEGA Epidemiology, \\ The University of Melbourne, Melbourne, Victoria, Australia; ${ }^{3}$ Department of Psychology, University of Swansea, Swansea, UK; ${ }^{4}$ Department of Anatomical \\ Pathology, The Alfred Hospital, Melbourne, Victoria, Australia; ${ }^{5}$ Department of Medicine, Monash University, Monash, Victoria, Australia
}

BACKGROUND: We aimed to assess whether 2D:4D measures are associated with breast cancer risk.

METHODS: We derived the ratio of the lengths of the index and ring fingers (2D:4D), and right minus left 2D:4D $\left(\Delta_{r}-1\right)$ from digit lengths measured from photocopies of participants' hands collected during a recent follow-up of the Melbourne Collaborative Cohort Study, a prospective study including 24469 women. Of the 9044 women with available data, we identified 573 incident breast cancer cases. Hazard ratios (HR) and 95\% confidence intervals (Cl) for a one standard deviation difference in 2D:4D measures were obtained from Weibull survival models, and linear regression models were used to examine potential associations between 2D:4D measures and age at menarche and menopause.

RESULTS: We found a direct association between left 2D:4D and breast cancer risk, an inverse association between $\Delta_{r-1}$ and risk of breast cancer, but no association between right 2D:4D and breast cancer risk. Among breast cancer cases, both right 2D:4D and $\Delta_{r-1}$ were inversely associated with age at diagnosis. We also observed associations between both right 2D:4D and $\Delta_{r-1}$ and age at menopause, with increasing digit ratio measures related to earlier mean age at menopause.

CONCLUSION: Digit ratio measures might be associated with breast cancer risk and age at onset of breast cancer. If confirmed in other studies, this suggests that lower exposure or sensitivity to prenatal testosterone might be associated with lower risk of breast cancer. British Journal of Cancer (2012) I07, I631-1636. doi:I0.1038/bjc.2012.4I8 www.bjcancer.com

Published online 18 September 2012

(c) 2012 Cancer Research UK

Keywords: breast cancer; hormones; digit ratio; 2D:4D; prenatal hormones

There is substantial evidence implicating androgens and oestrogens in the aetiology of breast cancer. Prospective studies have consistently reported that higher levels of endogenous oestrogens and androgens, and lower levels of sex hormone binding globulin (SHBG) are associated with risk of post-menopausal breast cancer (Key et al, 2002; Manjer et al, 2003; Missmer et al, 2004; ZeleniuchJacquotte et al, 2004; Kaaks et al, 2005b; Hankinson and Eliassen, 2007; Baglietto et al, 2010), and there is some evidence indicating similar associations with pre-menopausal breast cancer risk as well (Kaaks et al, 2005a; Eliassen et al, 2006). Additionally, many wellestablished risk factors for breast cancer such as age at menarche, age at menopause, hormone replacement therapy use, and duration of lactation can be considered measures of cumulative exposure to oestrogen that the breast epithelium is exposed to over time (Henderson and Feigelson, 2000). The potential importance of cumulative or critical exposure to sex hormones has led to consideration of in utero hormone factors that might influence later risk of breast cancer.

The ratio of the lengths of the index (2D) and ring (4D) fingers, expressed as the ratio $2 \mathrm{D}: 4 \mathrm{D}$, has been proposed as a marker of prenatal androgen action or sensitivity to androgens. The

\footnotetext{
*Correspondence: DC Muller; E-mail: david.muller@cancervic.org.au or Associate Professor G Severi; E-mail: gianluca.severi@cancervic.org.au Received 29 June 2012; revised 24 August 2012; accepted 27 August 2012; published online 18 September 2012
}

investigation of digit ratios as possible markers of androgen action in early life began with the long-recognised observation that, compared with women, adult males tend to have longer ring fingers relative to other fingers. Contemporary anthropological studies have found small but consistent sex differences in $2 \mathrm{D}: 4 \mathrm{D}$, with men having lower average 2D:4D than women (Manning et al, 1998; McIntyre, 2006; Hönekopp and Watson, 2010).

Several lines of evidence indicate that prenatal testosterone exposure, or underlying sensitivity to testosterone, is inversely related to $2 \mathrm{D}: 4 \mathrm{D}$, especially right $2 \mathrm{D}: 4 \mathrm{D}$, as well as being inversely related to the difference between right and left $2 \mathrm{D}: 4 \mathrm{D}\left(\Delta_{r-l}\right)$ (McIntyre, 2006; Breedlove, 2010). Recent evidence from a mouse model suggests that $2 \mathrm{D}: 4 \mathrm{D}$ depends critically on in utero exposure to androgens relative to oestrogen exposure, with higher testosterone relative to oestrogen leading to lower right $2 \mathrm{D}: 4 \mathrm{D}$ (Zheng and Cohn, 2011). Furthermore, there is evidence from mouse models that the sex hormones and genes involved in the differentiation of fetal 2D:4D may also be involved in mammary gland initiation. During the development of $2 \mathrm{D}: 4 \mathrm{D}$, there are at least 19 skeletogenic genes that are activated or deactivated by prenatal testosterone and oestrogen (Zheng and Cohn, 2011). Among these, there are three genes (Wnts, Fgfs, and FGFR1) that influence $T b x$ genes, which initiates mammary gland formation (Eblaghie et al, 2004). Thus, if fetal development of mammary glands is linked to predisposition to adult breast cancer then 2D:4D might be an indicator of this disease predisposition. Additionally, there is some evidence that the Sox9 gene, which is 
also activated or deactivated by prenatal testosterone oestrogen during development of 2D:4D (Zheng and Cohn, 2011), might be important for breast tumour initiation and metastasis (Chakravarty et al, 2011).

Cross sectional (Manning et al, 1998) and longitudinal (McIntyre et al, 2005; Trivers et al, 2006) evidence suggests that sex differences in $2 \mathrm{D}: 4 \mathrm{D}$ are unaffected by puberty, suggesting that $2 \mathrm{D}: 4 \mathrm{D}$ is established very early in life. It has also been shown that 2D : 4D measures are unrelated to adult circulating and salivary sex hormone concentrations (Hönekopp et al, 2007; Muller et al, 2011). This makes 2D:4D an excellent candidate biomarker for examining putative associations between prenatal testosterone exposure or sensitivity to testosterone and risk of disease. We aimed to assess whether $2 \mathrm{D}: 4 \mathrm{D}$ or $\Delta_{r-l}$ is associated with risk of breast cancer, as well as whether $2 \mathrm{D}: 4 \mathrm{D}$ measures are associated with the established risk factors age at menarche and age at menopause.

\section{MATERIALS AND METHODS}

\section{Study sample}

The MCCS is a prospective cohort study of 41514 people (24 469 women) who were aged between 27 and 81 years at baseline $(99.3 \%$ of whom were aged 40-69). Recruitment occurred between 1990 and 1994 in the Melbourne metropolitan area. Participants were recruited via the electoral rolls (enrolment to vote is compulsory for adults in Australia), advertisements, and community announcements in local media (e.g., television, radio, and newspapers). All participants provided written informed consent, and the study was approved by the Cancer Council Victoria Human Research Ethics Committee.

At baseline interview participants were asked about conventional risk factors such as reproductive history, hormone replacement therapy and oral contraceptive use, country of birth, physical activity, alcohol consumption, smoking habits, and highest level of education. Physical measurements including weight, height, and blood pressure were also taken, and each participant provided a blood sample. Full details of the MCCS baseline phase are published elsewhere (Giles and English, 2002). A face-to-face follow-up was conducted between 2003 and 2009 where - in addition to completing interviews, physical measurements, and providing a blood sample - participants had their hands photocopied for the purpose of measuring 2D:4D.

Women who attended face-to-face follow-up between 2003 and 2009 and had their hands photocopied were eligible for inclusion in this study $(N=9174)$. We excluded from the analysis women who had a confirmed diagnosis of invasive breast cancer or unknown primary tumour before enrolment in the cohort $(N=130)$. These exclusions left 9044 women available for analysis.

\section{Case ascertainment and classification}

Cases included women with a first diagnosis of invasive adenocarcinoma of the breast (WHO, 2000) during follow up from baseline to 1 January 2010. Cases were ascertained via linkage to the Victorian Cancer Registry, which covers the state in which the cohort resides, and the National Cancer Statistics Clearing House, which holds cancer incidence data from all Australian states. Women with in situ breast cancer were not counted as cases. The medical records of women with breast cancer were reviewed and their cancers classified according to tumour grade, and oestrogen (ER) and progesterone (PR) receptor status was assessed as positive or negative using immunohistochemistry techniques on archival tissue where the original diagnostic tumour slides were available, and supplemented by the ER and PR status obtained from the histopathology reports held at the Victorian Cancer Registry. The vital status of all participants was determined by linkage to the Victorian death records and the national death index.

\section{Measurement of 2D:4D}

During a face-to-face follow-up conducted during 2003-2009, participants had their hands photocopied for the purpose of measuring 2D:4D ratios. The length of the second (index) and fourth (ring) fingers were measured from photocopies of the surface of the hand using vernier calipers with a resolution of $0.01 \mathrm{~mm}$. Measurements were taken from the tip of the finger to the basal crease. Where two creases were visible at the base of the digit, the crease proximal to the palm was chosen. The length of the index finger was divided by the length of the ring finger to obtain $2 \mathrm{D}: 4 \mathrm{D}$, and $\Delta_{r-l}$ was calculated as the difference between right and left $2 \mathrm{D}: 4 \mathrm{D}$. The measurement was undertaken by a team of trained research assistants at Cancer Council Victoria.

\section{Statistical methods}

One-hundred photocopies were measured by each research assistant twice so as to assess inter and intraobserver reliability of the digit measurements. We fit mixed models to the raw digit lengths and 2D:4D ratios, with individual and research assistant entered into the model as crossed random effects. Intraclass correlation coefficients (ICC's) were calculated as the proportion of variance in digit length or digit ratio accounted for by between individual variation.

For analyses of breast cancer risk, follow-up began at baseline and continued until diagnosis of invasive breast cancer or cancer of unknown primary site, death, date left Australia, or the beginning of January 2010, whichever came first. Overall hazard ratios (HR) and 95\% confidence intervals (CI) for a one standard deviation increase in 2D:4D measures were obtained from Weibull survival models with age as the time axis.

To examine whether any association between 2D:4D and risk of breast cancer varies by age, we fit flexible parametric survival models (Lambert and Royston, 2009). For this method, we employed restricted cubic splines with five knots (evenly spaced with regard to the distribution of uncensored log survival times) to model the baseline hazard, and restricted cubic splines with one knot (placed at the median of the distribution of uncensored log survival times) to allow the HR for $2 \mathrm{D}: 4 \mathrm{D}$ measures to vary with age. The data duplication method was employed to fit competing risks Weibull models for tumour grade (well differentiated vs moderately differentiated $v s$ poorly or undifferentiated), and categories of ER and PR status (Lunn and McNeil, 1995). Briefly, this method involves augmenting each person in the data set with an additional observation for every competing outcome, effectively creating a stratum for each event. In each stratum, the variable indicating failure is set according to whether the person experienced the particular event relevant to the stratum, with those failing due to another event censored. The data are modelled as usual, with the addition of interaction terms between covariates of interest and variables identifying the strata.

We did not adjust our survival models for known breast cancer risk factors such as age at menarche and age at menopause, as we consider these to be intervening rather than potentially confounding variables. Instead, we investigated possible associations between 2D:4D measures and hormonally related risk factors directly. Linear regression models were used to estimate the effect of a one standard deviation change in 2D:4D measures on age at menopause and age at menarche, adjusted for country of birth. We also examined whether $2 \mathrm{D}: 4 \mathrm{D}$ measures were associated with age at diagnosis for the breast cancer cases intake by fitting linear regression models of age at diagnosis on restricted cubic spline 
functions of 2D:4D measures. These spline functions were constrained to be linear beyond 3 standard deviations from the mean, and had 3 interior knots placed at the 25th, 50th, and 75th percentiles of the measure.

Due to the strong correlation between left and right 2D:4D (0.56 in this sample), separate models were fit for left and right 2D:4D. Additionally, we fit separate models for $\Delta_{r-l}$. All models were adjusted for country of birth. The likelihood ratio test was used to test main effects, and the Wald test was used to test for heterogeneity by tumour grade and ER/PR status in the competing risks models. All analyses were performed using Stata/SE 11.2 for Linux 64 bit (Stata Corporation, College Station, TX, USA).

\section{RESULTS}

Inter and intraobserver reliability was high for raw digit measurements, with ICC's for left and right, index and ring fingers all being greater than 0.95 . Intraclass correlation coefficients for $2 \mathrm{D}: 4 \mathrm{D}$ ratio were slightly lower than those for raw digit measurements ( 0.80 for right and 0.73 for left $2 \mathrm{D}: 4 \mathrm{D})$, but still suggest that the observed variability in digit ratio is largely due to between individual differences rather than measurement error.

Of the 9044 women available for this study, we identified 573 incident breast cancer cases during a median follow-up of 16 years
4 months per participant (a total of 145328 person-years at risk were observed). Characteristics of the study population are shown in Table 1. Cases were slightly older than non-cases on average, with median age at baseline of 55 years compared with 53 . Seventyfive percent of the participants were born in Australia, New Zealand, or the United Kingdom.

Estimates from Weibull survival models are presented in Table 2. We found an inverse association between $\Delta_{r-l}$ and risk of breast cancer, with a one standard deviation increase in $\Delta_{r-l}$ associated with a $9 \%$ lower risk of breast cancer $(\mathrm{HR}=0.91,95 \%$ CI $0.84-0.99, P=0.03)$. Conversely, there was a direct association between left $2 \mathrm{D}: 4 \mathrm{D}$ and breast cancer risk ( $\mathrm{HR}=1.09,95 \% \mathrm{CI}$ 1.00-1.19). No overall association was observed between right $2 \mathrm{D}: 4 \mathrm{D}$ and risk of breast cancer $(\mathrm{HR}=0.99,95 \%$ CI $0.91-1.08$, $P=0.88)$.

Time varying estimates of HRs and $95 \%$ CIs associated with a one standard deviation increase in $2 \mathrm{D}: 4 \mathrm{D}$ measures are plotted in Figure 1 . The estimated associations do not vary substantially over time, although there is some indication that the inverse association between $\Delta_{r-l}$ and breast cancer risk is stronger for older women. For instance, the HR for a one standard deviation increase in $\Delta_{r-l}$ at age 50 is approximately $1(95 \% \mathrm{CI} \approx 0.80-1.20)$, whereas at age 70 , it is approximately $0.83(95 \% \mathrm{CI} \approx 0.78-0.95)$. Predicted mean age at diagnosis for breast cancer cases as a function of 2D:4D measures is plotted in Figure 2. Although there appears to be no trend in age at diagnosis with increasing left $2 \mathrm{D}: 4 \mathrm{D}$,

Table I Characteristics of the 9044 women by breast cancer case status

\begin{tabular}{|c|c|c|c|}
\hline & Cases $(n=573)$ & Controls $(n=847 I)$ & Total $(n=9044)$ \\
\hline Age at baseline (median, interquartile range) & $55(48-62)$ & $53(47-60)$ & $54(47-61)$ \\
\hline Right 2D: 4D (mean, standard deviation) & $0.961(0.038)$ & $0.961(0.037)$ & $0.96 \mid(0.037)$ \\
\hline Left 2D:4D (mean, standard deviation) & $0.969(0.037)$ & $0.966(0.036)$ & $0.966(0.036)$ \\
\hline$\Delta_{r-1} 2 \mathrm{D}: 4 \mathrm{D}$ (mean, standard deviation) & $-0.008(0.033)$ & $-0.005(0.034)$ & $-0.005(0.034)$ \\
\hline Age at menopause (median, interquartile range) & $50(48-53)$ & $50(47-52)$ & $50(47-52)$ \\
\hline \multicolumn{4}{|l|}{ Age at menarche (n, \%) } \\
\hline$<12$ & $99(17)$ & $1378(16)$ & $1477(16)$ \\
\hline 12 & I $18(20)$ & |65| (20) & $1769(20)$ \\
\hline 13 & $150(26)$ & $2295(27)$ & $2445(27)$ \\
\hline$\geqslant 14$ & $204(36)$ & $3128(37)$ & $3332(37)$ \\
\hline \multicolumn{4}{|l|}{ Country of birth (n, \%) } \\
\hline Australia, New Zealand, United Kingdom & $491(86)$ & $6303(74)$ & $6794(75)$ \\
\hline Italy & $57(10)$ & $1355(16)$ & $1412(16)$ \\
\hline Greece & $25(4)$ & $813(10)$ & $838(9)$ \\
\hline
\end{tabular}

Table 2 HRs and 95\% Cls for 2D:4D and breast cancer risk ${ }^{\mathrm{a}}$

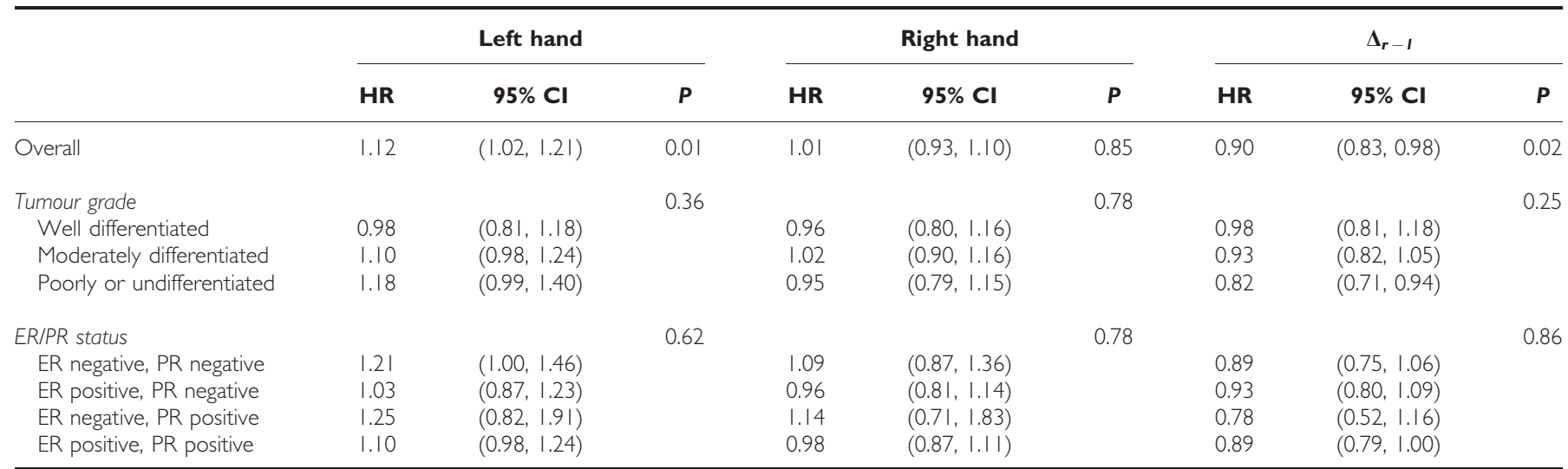

aResults estimated by Weibull survival models with age as the time axis, adjusted for country of birth. 2D:4D measures were standardised so HRs reflect a I-s.d. increase. P-values are from likelihood ratio tests of the overall coefficients, and Wald tests of heterogeneity between the HRs by tumour grade and ER and PR status. 

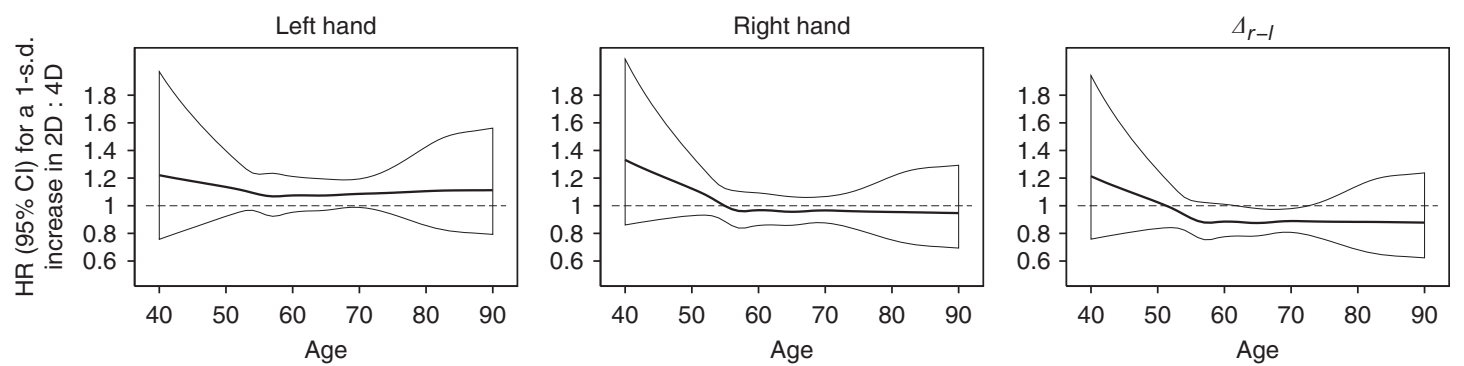

Figure I Time varying HR and 95\% Cl for a I s.d increase in 2D:4D measures from flexible parametric time to event models, adjusted for country of birth.
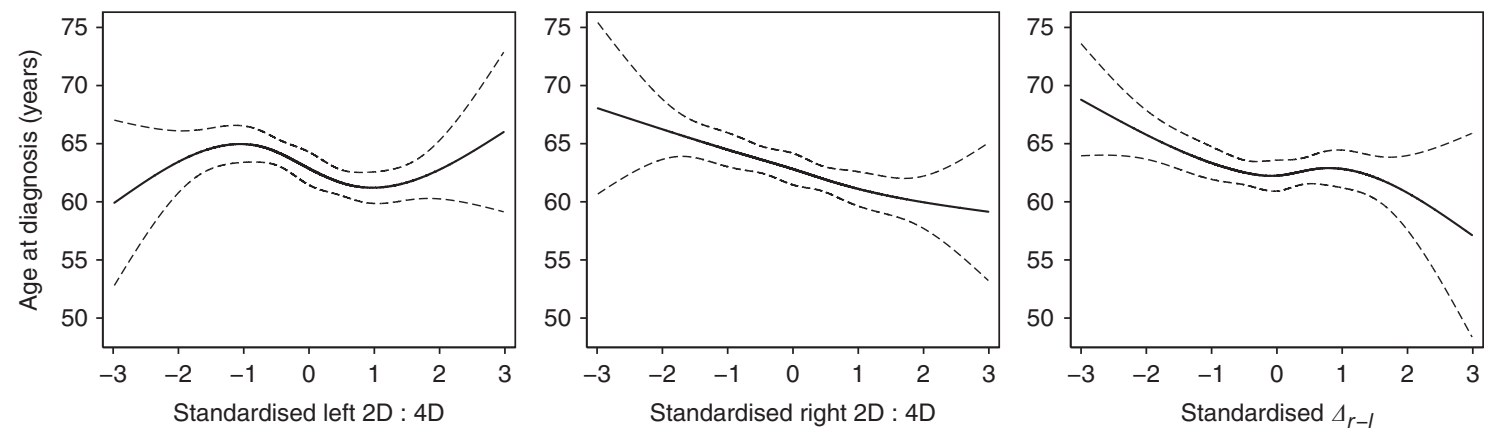

Figure 2 Predicted mean age at diagnosis and as a function of standardised 2D:4D measures with 95\% Cl.

Table 3 Hormone-related breast cancer risk factors and 2D:4D measures $^{\mathrm{a}}$

\begin{tabular}{lcccccccc}
\hline & \multicolumn{3}{c}{ Age at menarche } & & \multicolumn{3}{c}{ Age at menopause } \\
\cline { 2 - 3 } & $\begin{array}{c}\text { Mean } \\
\text { difference }\end{array}$ & $\mathbf{9 5 \%} \mathbf{~ C l}$ & $\boldsymbol{P}$ & $\begin{array}{c}\text { Mean } \\
\text { difference }\end{array}$ & $\mathbf{9 5 \%} \mathbf{~ C l ~}$ & $\mathbf{P}$ \\
\hline Left hand & -0.02 & $(-0.05,0.01)$ & 0.24 & -0.06 & $(-0.22,0.09)$ & 0.40 \\
Right hand & -0.03 & $(-0.06,0.01)$ & 0.12 & -0.25 & $(-0.41,-0.10)$ & 0.001 \\
$\Delta_{r-1}$ & -0.01 & $(-0.04,0.03)$ & 0.64 & -0.16 & $(-0.31,-0.01)$ & 0.04 \\
\hline
\end{tabular}

a Results estimated by linear regression models of age at menarche and age at menopause on standardised 2D:4D measures, adjusting for country of birth. Coefficients represent the mean difference in years for a $I$-s.d. increase in the 2D:4D measure. $P$-values are from likelihood ratio tests of the regression coefficients.

age at diagnosis tends to decrease with increasing right $2 \mathrm{D}: 4 \mathrm{D}$ and $\Delta_{r-l}$.

To examine whether estimates varied by tumour grade or ER and PR status, we fit competing risks Weibull survival models. Results from these models are also presented in Table 2. The association between $\Delta_{r-l}$ and risk of breast cancer was strongest for poorly or undifferentiated tumours $(\mathrm{HR}=0.81,95 \% \mathrm{CI} 0.71-$ 0.94; compared with $\mathrm{HR}=0.93,95 \%$ CI $0.82-1.05$ for moderately differentiated tumours; and $\mathrm{HR}=0.98,95 \%$ CI $0.81-1.18$ for welldifferentiated tumours), though there was little statistical evidence of heterogeneity between these HRs $(P=0.25)$. There was little difference in the estimated HRs when they were separately estimated by ER and PR status, and formal statistical tests for heterogeneity of the HRs yielded no evidence that the associations between 2D:4D measures and breast cancer risk differed according to the hormone receptor status of the tumour (all $P$ values $>0.62$ ).

Results from regressions of age at menarche and age at menopause on standardised digit ratio measures are presented in Table 3. Mean age at menopause was slightly reduced with increasing right $2 \mathrm{D}: 4 \mathrm{D}(-0.25$ years, $95 \% \mathrm{CI}-0.41$ to -0.10 , $P=0.001)$ and increasing $\Delta_{r-l}(-0.16$ years, $95 \%$ CI -0.31 to
$-0.01, P=0.04)$. There was no association between left $2 \mathrm{D}: 4 \mathrm{D}$ and age of menopause, nor were there any associations between 2D : 4D measures and age at menarche.

\section{DISCUSSION}

We found an association between low $\Delta_{r-l}$, a marker of higher prenatal exposure or sensitivity to testosterone, and breast cancer risk. This association might be driven by the observed direct association between left $2 \mathrm{D}: 4 \mathrm{D}$ and breast cancer risk, given that we did not observe any association between right $2 \mathrm{D}: 4 \mathrm{D}$ and risk of breast cancer. We also observed a suggestion that the association between $\Delta_{r-l}$ and breast cancer risk might be strongest for poorly or undifferentiated tumours. Both right $2 \mathrm{D}: 4 \mathrm{D}$ and $\Delta_{r-l}$ were inversely associated with age at diagnosis, with cases with higher $2 \mathrm{D}: 4 \mathrm{D}$ measures presenting at a younger age. No 2D:4D measures were associated with age at menarche, but increasing right $2 \mathrm{D}: 4 \mathrm{D}$ and $\Delta_{r-l}$ were both associated with slightly earlier age at menopause.

The apparently contradictory overall results, in which we observe a direct association between left $2 \mathrm{D}: 4 \mathrm{D}$ and risk, an inverse association between $\Delta_{r-l}$ and risk, and no association between right $2 \mathrm{D}: 4 \mathrm{D}$ and risk, must be considered in light of the evidence connecting 2D:4D measures to prenatal exposure and sensitivity to testosterone. Evidence to date suggests that both right $2 \mathrm{D}: 4 \mathrm{D}$ and $\Delta_{r-l}$ are inversely associated with prenatal exposure and sensitivity to testosterone, whereas there is only relatively weak evidence of any association with left 2D:4D (Breedlove, 2010; Hönekopp and Watson, 2010). Furthermore, there is some evidence indicating that $\Delta_{r-l}$ is a stronger correlate of exposure or sensitivity to prenatal testosterone than right 2D : 4D (Manning et al, 2003; Hurd et al, 2011). We therefore focus our interpretation to results from analyses of $\Delta_{r-l}$ and right 2D:4D, though we acknowledge the possibility that direct interpretation of the association between left $2 \mathrm{D}: 4 \mathrm{D}$ and breast cancer risk may also be possible once left $2 \mathrm{D}: 4 \mathrm{D}$ is better characterised. 
Our study has the advantage of being a large, population-based cohort with complete follow-up in terms of cancer diagnosis. Digit measurements were made with a high degree of reliability by trained research assistants. Another advantage of our study is the ability to investigate associations by tumour grade, and ER and PR status. A limitation of our study is that not all participants attended follow-up, and thus we do not have 2D:4D measures available for every participant (complete data for the present study were available for $37 \%$ of the women in the cohort). If $2 \mathrm{D}: 4 \mathrm{D}$ is associated with disease severity and if disease severity is in turn associated with attendance, estimated associations could be biased toward the null. As there is evidence that $2 \mathrm{D}: 4 \mathrm{D}$ measures are stable over time (McIntyre et al, 2006; Trivers et al, 2006), we consider it appropriate to analyse these data prospectively, despite the retrospective collection of $2 \mathrm{D}: 4 \mathrm{D}$.

A previous study by Manning et al found an association between left $2 \mathrm{D}: 4 \mathrm{D}$ and age at onset of breast cancer such that women with high left 2D:4D presented with cancer earlier (Manning and Leinster, 2001). Interpretation of such an effect is difficult; however, as any association between left $2 \mathrm{D}: 4 \mathrm{D}$ and prenatal androgen exposure or sensitivity has not been well characterised. We found no trend in age at diagnosis of breast cancer with left 2D : 4D, but we did observe inverse associations between both right 2D:4D and $\Delta_{r-l}$ and age of diagnosis for breast cancer cases. Despite these associations, the estimated HRs for breast cancer risk did not vary substantially with age.

Although no other studies have assessed 2D:4D in relation to breast cancer risk, numerous factors thought to reflect prenatal or intrauterine sex hormone exposure have been investigated. For instance, several studies have reported associations between birth size measurements such as weight, length, and head circumference and risk of breast cancer in adulthood (Xue and Michels, 2007). These measures have been shown to correlate with maternal oestrogen and umbilical cord dehydroepiandrosterone concentrations, indicating that higher intrauterine exposure to sex hormones might increase later risk of breast cancer (Troisi et al, 2003). These associations are generally consistent with our finding that higher $\Delta_{r-l}$ is associated with decreased breast cancer risk; however, birth size measures appear to reflect both oestrogens and androgens, whereas $\Delta_{r-l}$ is thought to reflect greater sensitivity or exposure to prenatal testosterone only.

Given that $\Delta_{r-l}$ is a supposed inverse correlate of prenatal testosterone exposure, our results lead us to speculate on how in utero testosterone exposure might increase risk of breast cancer in adulthood. It is known that oestrogen can directly stimulate the proliferation of breast cells, whereas the effect of androgens is unclear. Breast cancer cell line studies have produced conflicting results, with most studies suggesting that androgens have an apoptotic and antiproliferative effect, and others finding a direct proliferative effect of androgens on breast cancer cells (Somboonporn et al, 2004). It is more likely that androgens exert any proliferative effects indirectly, after conversion to oestrogen by the aromatase enzyme (Henderson and Feigelson, 2000; Somboonporn et al, 2004). Although we can only speculate as to whether in utero testosterone exposure exerts effects directly or indirectly via aromatase conversion to oestrogen, and assuming that lower $\Delta_{r-l}$ reflects higher testosterone exposure for a given level of oestrogen, the observed inverse association between $\Delta_{r-l}$ and breast cancer risk, if confirmed, might reflect an effect of cumulative oestrogen exposure, or possibly critical exposure to oestrogen in utero. This interpretation is consistent with the argument that established risk factors such as early menarche and

\section{REFERENCES}

Althuis MD, Fergenbaum JH, Garcia-Closas M, Brinton LA, Madigan MP, Sherman ME (2004) Etiology of hormone receptor-defined breast cancer: late menopause can be considered markers of cumulative dose of oestrogen (Henderson and Feigelson, 2000). To fully interpret these results, however, further research is required to better characterise the link between prenatal sex hormones and 2D:4D measures, and also to assess whether it is reasonable to assume that aromatic conversion of testosterone to oestrogen can lead to an increased oestrogenic effect in utero as it does in adulthood.

There is evidence to suggest that tumours classified by ER and PR expression might be aetiologically distinct, as well as having different clinical, pathological, and molecular features (Althuis et al, 2004). In the present study, estimated HRs did not vary substantially in relation to tumour ER and PR status; however, due to small numbers of cases in the strata, we had limited statistical power to detect heterogeneity. We did observe some indication that the association between $\Delta_{r-l}$ and breast cancer risk might be slightly stronger for poorly or undifferentiated tumours; however, there was little statistical evidence to support heterogeneity by tumour grade. Also, few previous studies of hormonal factors and breast cancer have reported results stratified by tumour grade. Given the lack of both external supporting evidence and cogent theory, it is difficult to meaningfully interpret this finding.

If in utero testosterone exposure does impact upon risk of breast cancer in adulthood, it is plausible that its effect might be mediated by other hormonal factors. Late age at menopause is an established risk factor for breast cancer (Henderson and Feigelson, 2000). Our finding that increasing right $2 \mathrm{D}: 4 \mathrm{D}$ and $\Delta_{r-l}$ are associated with slightly lower age at menopause is therefore consistent with age at menopause potentially mediating any association between in utero testosterone exposure and breast cancer risk.

In conclusion, we found no association between right $2 \mathrm{D}: 4 \mathrm{D}$ and risk of breast cancer, but we did find a modest inverse association between $\Delta_{r-l}$ and risk of breast cancer. High $\Delta_{r-l}$ is an indicator of lower exposure or sensitivity to prenatal testosterone, and thus our results suggest that lower prenatal testosterone exposure might be associated with lower risk of breast cancer. The association between breast cancer risk and $\Delta_{r-l}$ was slightly stronger for poorly or undifferentiated tumours. We also observed inverse associations between both right 2D:4D and $\Delta_{r-l}$ and age at menopause. Further research is required to better characterise the link between prenatal sex hormone exposure and 2D:4D measures, as well as the role of androgen exposure throughout the lifespan in the aetiology of breast cancer.

\section{ACKNOWLEDGEMENTS}

This study was made possible by the contribution of many people, including the original investigators, the Program Manager, and the diligent team who recruited the participants and who continue working on follow-up. We would like to express our gratitude to the many thousands of Melbourne residents who continue to participate in the study. We would like to acknowledge the work of Juliet Anderson, Lily Laskaris, and Judith Heads who measured the vast majority of the digits. This work was supported by grants from the National Health and Medical Research Council (251533, 209057, 504711) and the National Breast Cancer Foundation, and was further supported by infrastructure provided by the Cancer Council Victoria. Cohort recruitment was funded by VicHealth and the Cancer Council Victoria. JLH is a NHMRC Australia Fellow.

\section{Conflict of interest}

The authors declare no conflict of interest. 
Baglietto L, Severi G, English DR, Krishnan K, Hopper JL, McLean C, Morris HA, Tilley WD, Giles GG (2010) Circulating steroid hormone levels and risk of breast cancer for postmenopausal women. Cancer Epidemiol Biomarkers Prev 19: 492-502

Breedlove SM (2010) Minireview: Organizational hypothesis: instances of the fingerpost. Endocrinology 151: 4116-4122

Chakravarty G, Moroz K, Makridakis NM, Lloyd SA, Galvez SE, Canavello PR, Lacey MR, Agrawal K, Mondal D (2011) Prognostic significance of cytoplasmic SOX9 in invasive ductal carcinoma and metastatic breast cancer. Exp Biol Med 236: 145-155

Eblaghie MC, Song SJ, Kim JY, Akita K, Tickle C, Jung HS (2004) Interactions between FGF and Wnt signals and Tbx3 gene expression in mammary gland initiation in mouse embryos. J Anat 205: 1-13

Eliassen AH, Missmer SA, Tworoger SS, Spiegelman D, Barbieri RL, Dowsett M, Hankinson SE (2006) Endogenous steroid hormone concentrations and risk of breast cancer among premenopausal women. J Natl Cancer Inst 98: 1406-1415

Giles GG, English DR (2002) The melbourne collaborative cohort study. IARC Sci Publ 156: 69-70

Hankinson SE, Eliassen AH (2007) Endogenous estrogen, testosterone and progesterone levels in relation to breast cancer risk. J Steroid Biochem Mol Biol 106: 24-30

Henderson BE, Feigelson HS (2000) Hormonal carcinogenesis. Carcinogenesis 21: 427-433

Hönekopp J, Bartholdt L, Beier L, Liebert A (2007) Second to fourth digit length ratio (2D:4D) and adult sex hormone levels: new data and a metaanalytic review. Psychoneuroendocrinology 32: 313-321

Hönekopp J, Watson S (2010) Meta-analysis of digit ratio 2D:4D shows greater sex difference in the right hand. Am J Hum Biol 22: 619-630

Hurd PL, Vaillancourt KL, Dinsdale NL (2011) Aggression, digit ratio and variation in androgen receptor and monoamine oxidase a genes in men. Behav Genet 41: 543-556

WHO (2000) International Classification of Diseases for Oncology, 3rd edn (ICD-O-3)

Kaaks R, Berrino F, Key T, Rinaldi S, Dossus L, Biessy C, Secreto G, Amiano P, Bingham S, Boeing $\mathrm{H}$, de Mesquita HBB, Chang-Claude J, Clavel-Chapelon F, Fournier A, van Gils CH, Gonzalez CA, Gurrea AB, Critselis E, Khaw KT, Krogh V, Lahmann PH, Nagel G, Olsen A, Onland-Moret NC, Overvad K, Palli D, Panico S, Peeters P, Quirós JR, Roddam A, Thiebaut A, Tjønneland A, Chirlaque MD, Trichopoulou A, Trichopoulos D, Tumino R, Vineis P, Norat T, Ferrari P, Slimani N, Riboli E (2005a) Serum sex steroids in premenopausal women and breast cancer risk within the European Prospective Investigation into Cancer and Nutrition (EPIC). J Natl Cancer Inst 97: 755-765

Kaaks R, Rinaldi S, Key TJ, Berrino F, Peeters PH, Biessy C, Dossus L, Lukanova A, Bingham S, Khaw KT, Allen NE, Bueno-de Mesquita HB, van Gils CH, Grobbee D, Boeing H, Lahmann PH, Nagel G, Chang-Claude J, Clavel-Chapelon F, Fournier A, Thiébaut A, González CA, Quirós JR Tormo MJ, Ardanaz E, Amiano P, Krogh V, Palli D, Panico S, Tumino R, Vineis P, Trichopoulou A, Kalapothaki V, Trichopoulos D, Ferrari P, Norat T, Saracci R, Riboli E (2005b) Postmenopausal serum androgens, oestrogens and breast cancer risk: the European prospective investigation into cancer and nutrition. Endocr Relat Cancer 12: 1071-1082
Key T, Appleby P, Barnes I, Reeves G, Endogenous Hormones and Breast Cancer Collaborative Group (2002) Endogenous sex hormones and breast cancer in postmenopausal women: reanalysis of nine prospective studies. J Natl Cancer Inst 94: 606-616

Lambert PC, Royston P (2009) Further development of flexible parametric models for survival analysis. Stata J 9(26): 265-290

Lunn M, McNeil D (1995) Applying Cox regression to competing risks. Biometrics 51: 524-532

Manjer J, Johansson R, Berglund G, Janzon L, Kaaks R, Agren A, Lenner P (2003) Postmenopausal breast cancer risk in relation to sex steroid hormones, prolactin and SHBG (Sweden). Cancer Causes Control 14: 599-607

Manning JT, Bundred PE, Newton DJ, Flanagan BF (2003) The second to fourth digit ratio and variation in the androgen receptor gene. Evol Hum Behav 24: 399-405

Manning JT, Leinster SJ (2001) Re: The ratio of 2nd to 4th digit length and age at presentation of breast cancer: a link with prenatal oestrogen? Breast 10: 355-357

Manning T, Scutt D, Wilson J, Lewis-Jones DI (1998) The ratio of 2nd to 4th digit length: a predictor of sperm numbers and concentrations of testosterone, luteinizing hormone and oestrogen. Hum Reprod 13: 3000-3004

McIntyre MH (2006) The use of digit ratios as markers for perinatal androgen action. Reprod Biol Endocrinol 4: 10-10

McIntyre MH, Cohn BA, Ellison PT (2006) Sex dimorphism in digital formulae of children. Am J Phys Anthropol 129: 143-150

McIntyre MH, Ellison PT, Lieberman DE, Demerath E, Towne B (2005) The development of sex differences in digital formula from infancy in the Fels Longitudinal Study. Proc Biol Sci 272: 1473-1479

Missmer SA, Eliassen AH, Barbieri RL, Hankinson SE (2004) Endogenous estrogen, androgen, and progesterone concentrations and breast cancer risk among postmenopausal women. J Natl Cancer Inst 96: 1856-1865

Muller DC, Giles GG, Bassett J, Morris HA, Manning JT, Hopper JL, English DR, Severi G (2011) Second to fourth digit ratio (2D:4D) and concentrations of circulating sex hormones in adulthood. Reprod Biol Endocrinol 9: 57-57

Somboonporn W, Davis SR, National Health and Medical Research Council (2004) Testosterone effects on the breast: implications for testosterone therapy for women. Endocr Rev 25: 374-388

Trivers R, Manning J, Jacobson A (2006) A longitudinal study of digit ratio (2D:4D) and other finger ratios in Jamaican children. Horm Behav 49: $150-156$

Troisi R, Potischman N, Roberts J, Siiteri P, Daftary A, Sims C, Hoover RN (2003) Associations of maternal and umbilical cord hormone concentrations with maternal, gestational and neonatal factors (United States). CCC 14: 347-355

Xue F, Michels KB (2007) Intrauterine factors and risk of breast cancer: a systematic review and meta-analysis of current evidence. Lancet Oncol 8: $1088-1100$

Zeleniuch-Jacquotte A, Shore RE, Koenig KL, Akhmedkhanov A, Afanasyeva Y, Kato I, Kim MY, Rinaldi S, Kaaks R, Toniolo P (2004) Postmenopausal levels of oestrogen, androgen, and SHBG and breast cancer: long-term results of a prospective study. Br J Cancer 90: 153-159

Zheng Z, Cohn MJ (2011) Developmental basis of sexually dimorphic digit ratios. Proc Natl Acad Sci USA 108: 16289-16294

This work is published under the standard license to publish agreement. After 12 months the work will become freely available and the license terms will switch to a Creative Commons Attribution-NonCommercial-Share Alike 3.0 Unported License. 